\title{
The welfare model: A paradigm shift in medical decision- making
}

\author{
Brian YL Chan ${ }^{1}$, Joanne EY Chin ${ }^{1 *}$ and Lalit Kumar Radha Krishna ${ }^{1-4}$ \\ ${ }^{1}$ Duke-NUS Graduate Medical School, Class of 2017, Singapore \\ ${ }^{2}$ Yong Loo Lin School of Medicine, National University of Singapore, Singapore \\ ${ }^{3}$ Lien Centre for Palliative Care, Duke-NUS Graduate Medical School, Singapore \\ ${ }^{4}$ Division of Palliative Medicine, National Cancer Centre, Singapore
}

\begin{abstract}
Medical decision-making has evolved from being a physician's prerogative to an endeavour that is increasingly patient-centric. Autonomy, a key feature of patientcentered care in the West, emphasizes the preservation of a patient's wishes in an environment free from external influences. In Singapore, patient autonomy is often considered in the context of the family unit, resulting in a family-led decision-making process that often leads to collusion. The key to minimizing the effects of such coercive factors may lie in a welfare model that assembles healthcare professionals from various specialties into a multidisciplinary team, with the sole purpose of upholding patient welfare. Although the welfare model is a clinically relevant and ethically sensitive approach which considers a patient's condition, goals of therapy, family support and underlying socioeconomical factors, there are still limits to its practical implementations. By applying the welfare model in the context of endof-life decision-making, this article explores the challenges in easing the tension between physician paternalism, patient preference and familial determination, in an attempt to provide holistic and individualised care to patients.
\end{abstract}

\section{Introduction to medical decision-making}

There are many medical decision-making models. Dominating the decision making landscape till recently was medical paternalism, which saw health-related decisions rest almost exclusively with physicians. Physicians, guided by a professional code of ethics and genuine concern for patient's welfare, were expected to act in their patient's best interests [1]. Backing this position was the weight placed upon a physician's training and expertise to evaluate the risks and benefits of differing therapies and select the best treatment option for their patient. A rise in individual autonomy saw patients attempt to redress this imbalance in care determinations. Legal challenges to the position of physicians to trump the patient's rights to decide their own fate oversaw the decline of paternalism. Primacy of patient choice to determine their course of care has held sway since then, at least in the West [2].

\section{Conceptions of confucian personhood and its} implications upon local care determinations

From a western perspective, autonomy pivots upon an atomistic perspective of self-governance. This concept of autonomy translates into self-determination and freedom from external influences within the sphere of medical decision-making [3]. Efforts to instill this perspective into local culture however have been of limited success due to conflicts with prevailing culture. At its core, the differences between the Western inspired individualistic concepts of self-governance and Eastern led family centric beliefs lie in the way personhood or 'what makes you, you' are conceived. Rather than the individualistic approach to personhood that is envisaged in Western culture, Confucian concepts of personhood see personhood as a relational entity. According to Tsai's model of personhood, every person has a vertical and horizontal component [4]. The vertical component represents the autonomous person who is self-activated, self-determined, self-reliant and morally cultivated. However, this person does not exist in isolation. The horizontal component brings in the concept of relational autonomy, acknowledging that people are part of a wider relational network, with responsibilities towards family and society; confining medical decision-making to the patient alone would be tantamount to rejecting the inherent values of these relationships, denying the entwined nature of familial ties that see the impact of care determinations affect all who care and support the patient $[4,5]$. This is particularly relevant in societies that still depend upon family to care for their loved ones. All too often it is family members who must resign from their occupations to care for ailing parents and siblings, provide financial, emotional and physical support. This is seen as essentially meeting filial obligations to care for family elders for their earlier sacrifices. Policing compliance to these sociocultural beliefs are the wider family and community who would regard failure to effectively carry out these filial obligations as a 'loss of face' or in effect a loss of personal and familial honor [6,7]. Meeting filial obligations is also measured by continued care and support till death. This is frequently translated to a sense of non-abandonment. The manner that this obligation is interpreted has significant repercussions to care provisions. Whilst most families see their duty of non-abandonment as ensuring that adequate care is

Correspondence to: Chin En Yi Joanne, Duke-NUS Graduate Medical School, 8 College Road, Singapore 169857, Tel: +65 92971076, E-mail: chinjoanne@u.duke.nus.edu

Key words: palliative care, end of life care, medical decision-making, medical paternalism, welfare model

Received: July 05, 2015; Accepted: September 07, 2015; Published: September 10,2015 
provided to the patient right up to their demise and wherever possible, grant their final wishes, some families see it as a duty to 'continue fighting' even when conventional treatments are exhausted [6,7]. Not uncommonly, families pursue aggressive treatment options and attempt to use traditional remedies and unconventional options in direct contradiction to medical advice [6]. In part families see attempts to continue to pursue curative or simply life prolonging measures as a sign of maintaining 'hope', a key ingredient to their filial obligations. Maintenance of hope also sees families attempt to shield their loved ones from 'bad news', which is seen to negatively impact upon prognosis and goes hand-in-hand with local taboos about discussing death and dying for fear not only of dissipating 'hope' but of tempting 'fate' [6-10].

In the local setting, decision-making, particularly within the context of palliative care then becomes the prerogative of the entire family, overriding the values of individual choice and self-determination. Family members keen to uphold their filial obligations argue that indeed it is the family that knows the patient best, their wishes, goals and values [8-10]. It is they who must provide the financial, physical, psychological, and existential support as well as the practical support for the patients and thus are best placed to consider what can realistically be provided. Here the presence of coercive factors in the form of economic, social, cultural or religious considerations complicate familial care determinations and jeopardize patient care, particularly when meeting their filial obligations carry with it significant financial, physical, psychological and existential repercussions upon the family members themselves [8-10].

\section{Best interest model within the end of life setting}

Concerns of compromise to patient welfare have fuelled the translocation of the Best Interest Principle (BIP) as contained within Singapore's Mental Capacity Act to secure the interests of vulnerable patients and redress any potential biased decision making from family members [11,12]. However, on closer scrutiny, the application of the BIP is not without flaws. To better contextualize this concern set within the specific context of end of life care determinations, readers should be aware that there remains significant concerns particularly within the local palliative care setting that true autonomous decision making by the patient is a rarity. Aside from the previously discussed compromises to the patient's ability to participate meaningfully in care determinations, there is evidence of primary and secondary coercive factors that limit the ability of patient to cogitate upon their situation. Primary coercive factors refer to cognitive dysfunctions that are known to impact the deliberative functions of patients at the end of life. These would include impairment of conscious function, the presence of delirium and psychological disturbances, the general effect of the winding down of the dying, the impact of disease process and iatrogenic factors. These considerations are well discussed and have led to closer scrutiny of the decisions of patients particularly at the end of life. The concept of secondary coercive factors is introduced purely for convenience to encapsulate those considerations that lie beyond simple clinical considerations. These include the impact of social considerations such as the willingness or ability of the family to meet the wishes of the patients and the financial, practical, social, familial and cultural factors that curb choice and critically pressure decisions towards a specific direction $[9,13]$. This could include cultural pressure to die at home particularly in the eighth month of the Chinese calendar which would see patients who die away from home susceptible to becoming 'hungry ghosts', the social considerations of the impact of dying at home and the future value of their home and the inheritance of their children, the practical limitations of a discharge home when family members would have to give up their jobs to care for the patient, the financial considerations of prolonged stay at hospital or a hospice and the wish to die in hospital where care can be better met by professionals that must be balanced against the need to help the family show their filial duties which is important for their own social standings within the local settings.

The presence of such coercive factors that may not be plainly evident or easily delineated have led [14] to question if the BIP decision making process that is traditionally limited to the presence of competent decision-making capability ought to be respected in the same manner that it is in other clinical settings or even earlier within the patient's disease journey. Concern is that the BIP is unable to override the patient's wishes, even when the patient's life may be placed in jeopardy. To further contextualize these concerns is due consideration of Singaporean culture that places a premium on the value and preservation of life as evidenced by Singapore's unequivocal position on suicide, the prohibition of physician assisted suicide and euthanasia $[8,15,16]$. Unsurprisingly local society would be averse to having patients compromise their welfare and potentially their lives particularly in eliciting apparently competent decisions against medical advice such as an "at own risk" discharge. These wider considerations raise yet further concerns about the efficacy of the BIP model within the palliative care setting, not least the fallibility of its operator [17-20]. Singaporean physicians, who are usually the primary determiners of patient care, have been shown to be mainly clinical rather than holistic in their assessment of patients, raising concerns about their ability to act effectively.

\section{Welfare model}

A potential solution to prevailing concerns of preserving patient welfare in the face of coercive factors and complex psychosocial considerations may lie in Krishna et al. Welfare Model (WM) [14]. The WM is not an attempt to replace family-led decision-making with physician-led medical paternalism, but seeks instead to ensure that patient welfare, as determined holistically by a multidisciplinary team (MDT), is not compromised $[8,14]$. The WM dispenses with the notion of physicians as sole arbitrators and employs an MDT to holistically determine the best interests of patients [21-24]. An MDT is defined as a "group of people from different healthcare disciplines, meeting together at a given time to discuss the management of patients, as well as elaborate upon the various biopsychosocial, spiritual and cultural determinants that may be relevant to the provision of care and support to patients and their families". Each member of the team approaches the patient from their own clinical perspective, acknowledging them as autonomous individuals while simultaneously recognizing the influence of social, cultural, familial and economic factors. The team members work together in a seamless fashion, maintaining transparency and accountability and adhering to the current professional, clinical and legal guidelines with the central goal being, ensuring a holistic and balanced picture of the patient and their needs [21-24].

In the example of the patient who wished to be discharged home against medical advice, evaluation of the patient's social support could be carried out by the medical social worker (MSW) and the occupational therapist (OT). Visits can be made to assess the safety of the patient's home, taking into consideration his medical conditions. A physiotherapist (PT) and OT may assess his exercise tolerance, his safety awareness and ability to carry out his activities of daily living. The MSW and the nursing team may work to assess the needs of 
the family and their wishes whilst all team members may work to assess the patient's wishes and his capability but also his freedom to make informed decisions and his ability to care for himself. External considerations such as financial, family and social issues should also be assessed.

The findings of all the members of the MDT are presented during the review of the patient's case, where the team, as a whole, considers the facts and decides if it is in the patient's best interest to return home. It is the preservation of the patient's welfare that is central to the MDT and their actions are defined by prevailing clinical, professional and legal standards [21-24]. Therefore, while it may be in keeping with the principle of autonomy to discharge the patient, the MDT must determine if there is adequate care available at home and whether the patient's safety can be guaranteed. Under the aegis of the WM, withholding approval for discharge would be acceptable if the MDT have cause for concern. Such overruling of autonomous decisions would only come into being should there be adequate evidence that the patient will be put in harm's way. To be clear, whilst this decision to overrule the potentially autonomous decisions of the patient seem shocking to Western sensibilities cultured in the central concepts of autonomous choice, such decisions are not altogether contrary to local ideals still led by strong Confucian ideals and its core Principle of Beneficence $[6,8,25]$.

\section{The impact of collusion: A case study}

Madam C is an 82-year-old Chinese lady who fell and fractured her left hip after a syncopal episode. Her circumstances illustrate how collusion between the family and medical team can harm a patient. During her admission, she was discovered to have colon malignancy and a suspicious breast lump. Madam C's family struggled to come to terms with the news and the pursuant care determinations. They colluded amongst themselves to keep news of her condition from her and attempted to circumnavigate her involvement in her own care decisions, unsure of how she would respond to such news. Her family believed that such action was in keeping with their filial obligations to maintain "hope" and protect the patient from "bad news". Despite the medical team's advice to explain to her what was going on, Madam C's family continued to procrastinate, ostensibly trying to protect her from being 'traumatized' whilst believing that they were seeing out their duty of non-abandonment of the patient. In the context of the case, allowing Madam $\mathrm{C}$ to contend with the reality of her condition would be construed as 'destroying her hope' and would be tantamount to abandonment. Such a failure of filial obligations would invite a 'loss of face' or a loss of family honor in the eyes of their family and society, a fate fearfully avoided in local culture [6]. After a week's delay, Madam $\mathrm{C}$ developed hospital-acquired pneumonia which further complicated her care.

Recovery saw the patient make it clear that she desired to go home. However, she would likely suffer from bouts of abdominal pain for which the family believed they could not always be at hand to administer the medication and critically the patient would likely be alone at home for the better part of the day with the family out at work. The patient was neither aware of the risks of her condition nor the potential for falls and collapses that were deemed likely by the OT and physiotherapists following their assessment of her mobility and the adaptations around her home. The risks to the patient were significant and the continued collusion between the family members and the continued complicity of the medical team in this merely complicated the situation and reduced the ability of the patient to make valid decisions. Guided by the WM the medical team discussed the situation with the family, explaining the importance of notifying her of both her risks of complications and the potential benefits of treatment. With the family agreeing with the position of the medical team, they helped convince Madam C to undergo colorectal and breast surgeries following the repair of her left hip.

Madam C was discharged home with palliative care support two weeks later with her symptoms well controlled and her goals of care and treatment options established. Madam $\mathrm{C}$ also made her will before her discharge and was looking forward to putting a few other matters in order upon her discharge.

\section{Reflections upon the welfare model}

The WM, via an MDT approach, engages different professionals to achieve a holistic understanding of patients and their circumstances, with preservation of patients' welfare as the MDT's principal focus. This approach allows for improved clinical decision-making to better meet patients' needs. With multiple channels of input, the WM seems to be up to the challenge of providing satisfactory care in settings with varying sociocultural, clinical and legislative guidelines [14,25].

There are however, several potential pitfalls to its practical execution. One of the risks would be an imbalanced opinion that occurs when less experienced or vocal members feeling intimidated to share their perspectives in the presence of more senior figures. To ensure that all members of the MDT are participating, efforts should be made to encourage each individual to participate via respectful communication protocols agreed on by the team. Even then, how does once actively moderate the contributions and determine the proportion of input coming from each member?

Another challenge is with regard to the transparency and accountability of implementation. In medical decision-making, healthcare teams have the responsibility of prioritizing patient welfare at the highest level. However at times, due to a lack of understanding or peer-regulation, it may be easier for healthcare professionals to simply abide with a family's requests than to be an advocate for their patient's welfare. While it is true that no particular policy can provide adequate coverage for every possible situation in their healthcare journey, healthcare workers should be educated as far as possible on the merits of the WM and its importance to the therapeutic relationship. On the flip side, the WM is still somewhat paternalistic and authoritarian in nature; ironically, the intention to maintain welfare and improved quality of life through the promotion of autonomy, are only valid as long as autonomy does not adversely affect welfare. Will this be viable in a system where patients and their families have an increasing desire to determine their own management? Thus, the rationales of intervention must be carefully deliberated to ensure that the most balanced consensus is arrived at.

\section{Conclusion}

Medical decision-making has evolved and continues to do so in the changing landscape of sociocultural beliefs and values. Autonomy may enjoy the status of being 'first amongst equals' in most other clinical settings but careful understanding of local sociocultural and contextual considerations see it increasingly being trumped by the Principle of Beneficence. The advent of the WM, at least within the local end of life setting, highlights the need for care provisions to be contextually sensitive and patient centric and reaffirms the constant thread that traverses all decision making approaches, the need for evidence 
based medicine, holistic appraisal, accountability, justifiability and compliance with prevailing legal, clinical and professional standards.

\section{Acknowledgements}

The authors would like to acknowledge Dr. Deborah Susan Watkinson who passed away during the writing of this paper. Dr. Watkinson's guidance and support on conceptualizing the Welfare Model and in guiding the primary authors was critical to the success of this project.

\section{References}

1. Singapore Medical Council. Physician's Pledge. [document on the internet] Singapore Medical Council. [Updated 2014 Jan 11; cited 2015 June 21] Available from: http://www.healthprofessionals.gov.sg/content/hprof/smc/en/leftnav/becoming_a_ registereddoctor/registration/register_of_medical_practitioners/full_registration.html

2. Charles C, Gafni A, Whelan T (1999) Decision-making in the physician-patient encounter: revisiting the shared treatment decision-making model. SocSci Med 49: 651-661. [Crossref]

3. Padela AI, Malik AY, Curlin F, De Vries R (2015) [Re]considering Respect for Persons in a Globalizing World. Dev World Bioeth 15: 98-106.[Crossref]

4. Tsai DF (2001) How should doctors approach patients? A Confucian reflection on personhood. J Med Ethics 27: 44-50.[Crossref]

5. Chan TE, Peart NS, Chin J (2014) Evolving legal responses to dependence on families in New Zealand and Singapore healthcare. J Med Ethics 40: 861-865.[Crossref]

6. Ho ZJ, Radha Krishna LK, Yee CP (2010) Chinese familial tradition and Western influence: a case study in Singapore on decision making at the end of life. J Pain Symptom Manage 40: 932-937.[Crossref]

7. Cheng CY(1986) The Concept of face and its Confucian Roots. Journal of Chinese Philosophy 13: 329-348.

8. Krishna LKR(2011) Decision making at the end of life: A Singaporean Perspective. Asian Bioethics Review 3: 118-126.

9. Krishna LR (2012) Best interests determination within the Singapore context. Nurs Ethics 19: 787-799.[Crossref]
10. Krishna LK, Watkinson DS, Beng NL (2015) Limits to relational autonomy--the Singaporean experience. Nurs Ethics 22: 331-340. [Crossref]

11. Mental Capacity Act 2005. (c.9). London: HMSO.

12. Mental Capacity Act 2008. (c.177A). Singapore: AGC.

13. Krishna LKR, Menon S(2014) Understanding the Practice of Collusion on End of Life Care in Singapore. JMED Research.

14. Krishna LK, Watkinson DS, Beng NL (2015) Limits to relational autonomy--the Singaporean experience. Nurs Ethics 22: 331-340.[Crossref]

15. Pang MC (1999) Protective truthfulness: the Chinese way of safeguarding patients in informed treatment decisions. J Med Ethics 25: 247-253.[Crossref]

16. Chan CK, Yau MK (2009) Death preparation among the ethnic Chinese well-elderly in Singapore: an exploratory study. Omega (Westport) 60: 225-239.[Crossref]

17. Windish DM, Ratanawongsa N (2008) Providers' perceptions of relationships and professional roles when caring for patients who leave the hospital against medical advice.J Gen Intern Med 23: 1698-1707.[Crossref]

18. Fiscella K, Meldrum S, Barnett S (2007) Hospital discharge against advice after myocardial infarction: deaths and readmissions. Am J Med 120: 1047-1053.[Crossref]

19. Hwang SW, Li J, Gupta R, Chien V, Martin RE (2003) What happens to patients who leave hospital against medical advice? CMAJ 168: 417-420.[Crossref]

20. Anis AH, Sun H, Guh DP, Palepu A, Schechter MT, et al. (2002) Leaving hospital against medical advice among HIV-positive patients. CMAJ 167: 633-637.[Crossref]

21. Junnola T, Eriksson E, Salanterä S, Lauri S (2002) Nurses' decision-making in collecting information for the assessment of patients' nursing problems. $J$ ClinNurs 11: 186-196.[Crossref]

22. Kidger J, Murdoch J, Donovan JL, Blazeby JM (2009) Clinical decision-making in a multidisciplinary gynaecological cancer team: a qualitative study. BJOG 116: 511-517. [Crossref]

23. Amir Z, Scully J, Borrill C (2004) The professional role of breast cancer nurses in multi-disciplinary breast cancer care teams. Eur J OncolNurs 8: 306-314.[Crossref]

24. Lanceley A, Savage J, Menon U, Jacobs I (2008) Influences on multidisciplinary team decision-making. Int J Gynecol Cancer 18: 215-222.[Crossref]

25. Krishna L, Chin J (2011) Palliative Sedation within the Duty of Palliative Care within the Singaporean Clinical Context. Asian Bioethics Review 3: 201-215.

Copyright: $\odot 2015$ Chan BYL. This is an open-access article distributed under the terms of the Creative Commons Attribution License, which permits unrestricted use, distribution, and reproduction in any medium, provided the original author and source are credited. 